\title{
The Study of Permanent Magnets Synchronous Machine (PMSM) of the Autonomous Electric Power Supply System (ASE), compatible with the Concept of a More Electric Aircraft (MEA)
}

\author{
Lucjan Setlak ${ }^{1 *}$, Rafat Kowalik ${ }^{1}$
}

${ }^{1}$ Department of Avionics and Control Systems, Polish Air Force Academy, ul. Dywizjonu 303 nr 35, 08-521 Deblin

\begin{abstract}
Based on the analysis and mathematical models of synchronous electric machines (motor/generator), basing on permanent magnets, presented in this paper, the main importance of alternator $\mathrm{AC}$ power sources in the form of starter/generator (for conventional aircraft) and in the form of integrated unit starter (motor)/AC synchronous generator $\mathrm{S} / \mathrm{G}$ AC (with respect to advanced aircraft concept in terms of more electric aircraft) was highlighted. Additionally, through the analysis and selected simulations of the on-board autonomous power supply system of the modern aircrafts, sources of electrical energy (synchronous motor/generator, integrated unit starter/AC generator) were located in board autonomic power system ASE (EPS, PES). Main components of this system are the electro-energetic power system EPS and the energo-electronic power system PES. In addition, the analysis and exemplary simulations of main electricity sources based on mathematical models have contributed to highlighting the main practical applications in accordance with the concept of MEA.
\end{abstract}

\section{Introduction}

Currently, in modern aircrafts of the main airline companies, both civil aviation (Airbus, Boeing, etc.) and military (Lockheed Martin), can be seen continuous development in terms of electrical machines [1], [2], which occurs due to dynamic technological progress of analogous fields of science, especially the innovative power electronics systems PES, equipment and advanced materials, and what goes with it - the new integrated avionics [3]. Additionally, gradually increasing dynamics of changes in the board power supply in modern aviation can be seen, both in the field of civil aircrafts (Airbus, Boeing) for airplanes (A-380 and A350XWB, B-787), as well as for military aviation (Lockheed Martin) in terms of aircrafts JSF (Joint Strike Fighter) F-35 and F-22 Raptor. Changes in on-board power supply in modern aviation have a key impact on the rapidly developing concept of a more electric plane, including in particular the dominant role of advanced systems in the production or processing of $\mathrm{AC}$ and their main components (rectifiers, transducers, etc.), as well as the EPS system in the area of direct current (DC generator or generators, accumulators as emergency sources, electric energy storage tanks, fuel cells, etc.). When making an initial analysis of the dominant role of on-board alternating current and direct current DC power supply, it should be noted that the on-board power supply is usually based on main sources of synchronous electrical machinery (motor, generator ). In the case of "classic" aircraft, these are generators or integrated unit
DC motor/DC generator and generators of increased constant frequency (CF) $400 \mathrm{~Hz}$ of alternating current (AC). In turn, in the case of "More Electric Aircraft", they are the source generators or integrated units of variable frequency (VF) generators, ranging from 390$780[\mathrm{~Hz}]$.

In view of the above, the on-board power supply of a modern aircraft in line with the new trend of the "More Electric Aircraft" concept may be based on a PMSM synchronous generator or an integrated unit starter AS/G VF (Alternating/Starter Variable Frequency Generator) [4], [5].

Based on the above, modern aircraft use primarily 3phase synchronous machines (e.g. generators) as a source of high-power AC electricity. In addition, it is noted that such PMSM electric machines operate most effectively during a generative range of operation, i.e. in terms of power produced. This does not mean, however, that PMSM synchronous electric machines can not operate on a motor (starter) operating range, that is, in the start-up range. Later the paper discusses and presents mathematical models of synchronous PMSM electric machines on the example of a synchronous motor for both serial and parallel connections in the field of EPS power supply, which is the main ASE power supply system implemented on modern aircraft.

*Corresponding author: 1.setlak@,wsosp.pl, r.kowalik@,wsosp.pl 


\section{Analysis and mathematical model of ASE system compatible with the trend of a More Electric Aircraft}

Analysis and creating a mathematical model in the electro-energetic power system of a more electric aircraft was performed using an electric machine (motor/generator) based on permanent magnets PMSM. Proceeding with the mathematical description (model) of physical phenomena occurring in the electrical machine PMSM, responsible for the generation and transmission of electricity needed to power the main board equipment (aerial flight instruments, aircraft electrical equipment), implemented on a modern airplane, at the beginning you should consider the above issues with regard to the interaction of the magnetic field formed between the stator and the rotor of the electrical machine.

At the next stage of the analysis, examining the physical phenomena occurring in the PMSM electrical machine, particular attention was paid to the process of starting the engine. During the induction of the stator winding with alternating voltage, a magnetic field is generated in the PMSM electrical machine. The speed at which the rotor rotates in a unit of time is called the rotational speed of the synchronous motor. In the initial phase it was assumed that the engine was stationary. In order to start the synchronous electrical machine PMSM, you should rotate the machine rotor at a speed close to or equal to the engine rotational speed. At a later stage of the startup process, the rotor unit is driven by the energy supplied by the propulsion system of the aircraft. If the synchronous speed is reached by the electric machine, the DC power is supplied to the rotor winding and the motor starts. Once the engine is started, a magnetic field is generated at the same time. Then, at some point, the magnetic field created by the rotor enters the stator and the engine is running at a certain rotational speed. It should be noted that in the motor (starter) operating range, the PMSM electrical machine rotor rotates at a synchronous speed. In addition, the engine operating range allows the performance in a single coordinate system respective moments of rotation of the four permanent magnets fixedly connected to the stator.

The initial assumptions are that the magnetic field is generated in the right direction and that the direction of the magnetic field of the rotor coincides with the direction of the magnetic field appearing on the stator [6], [7]. Then, using Ampere's law relating the electromotive force (emf) and the distribution on the individual permanent magnets shown in Fig. 1, one can write a mathematical expression defining the electromotive force induced in the coil as

$$
F=B l_{0} i
$$

where $B$ is the magnetic induction of the stator; $l_{o}$ is the width of the coil, and $i$ determines the alternating current flowing through the coil.

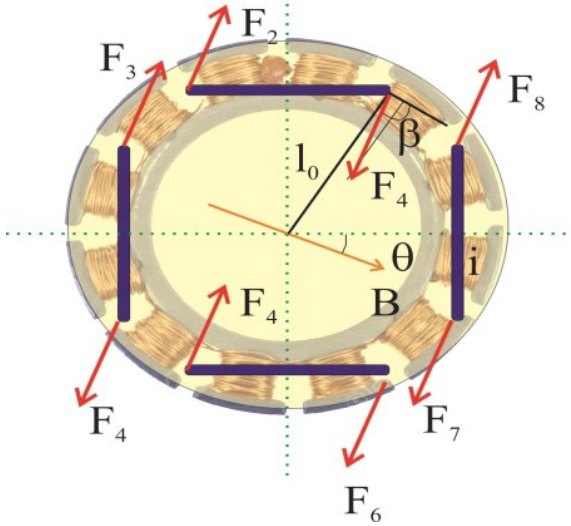

Fig. 1. Location of permanent magnets before starting the electric synchronous machine PMSM

Defining the value of the electromagnetic torque of a 4pole synchronous motor, the PMSM rotor can be used as a series connection of coils and resistors [8]. Resistance elements are responsible for creating electromagnetic forces $F_{k}, k=1, \ldots, 8$. Therefore, present in the analyzed electrical machine PMSM forces $F_{1}$ and $F_{2}$ act only on the first layers of the coil and are determined by (Fig. 2)

$$
\begin{aligned}
& F_{1 p r}=F_{1} \cos \beta_{1}=B l_{0} i \cos (\theta+\alpha) \\
& F_{2 p r}=F_{2} \cos \beta_{2}=B l_{0} i \cos (\alpha-\theta)
\end{aligned}
$$

where $\beta_{1}$ is the angle between the force vector $F_{1}$ and the perpendicular line defining the position of the permanent magnets relative to the motion of the magnetic field formed in the stator; $\beta_{2}$ the angle between the force vector $F_{2}$ and the perpendicular line, defining the position of the permanent magnets relative to the motion of the magnetic field formed in the stator; $\alpha$ defines the angle between the magnetic field vector and the magnetic field of the synchronous motor coil for the first coil layer; and $\theta$ the angle between the plane perpendicular to the direction of the vector defining the stator magnetic field and the plane of the magnetic field of the coil in the first layers of the coil.

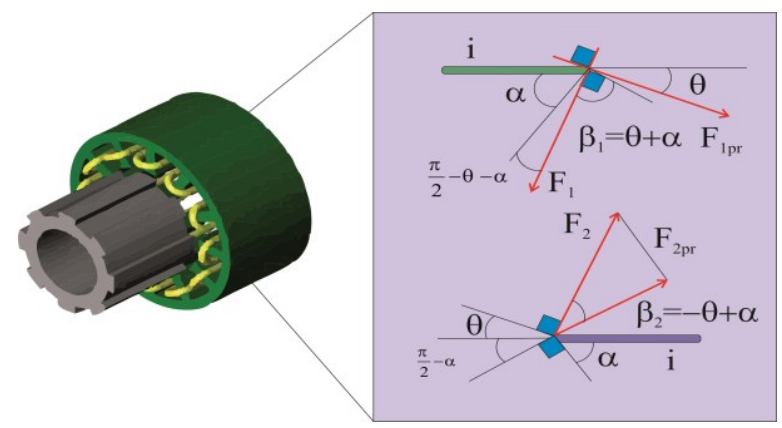

Fig. 2. Arrangement of vectors defining the position of permanent magnets

Next, taking into account the number of windings in the coil and the direction of rotation of the rotor, you can determine the mathematical relations that determine the torque acting on the coil. So the equations are as follows [9], [10] 


$$
\begin{aligned}
M_{1}=n l\left(F_{1 p r}+\right. & \left.F_{2 p r}\right) \\
& =n l B l_{0} i[\cos (\theta+\alpha) \\
& +\cos (\alpha-\theta)] \\
& =n\left(2 l l_{0} \cos \alpha\right) B i \cos \theta \\
& =n S B i \cos \theta
\end{aligned}
$$

where $n$ is the number of poles pairs of magnets in the induction motor; $l$ is the length of the vector between individual permanent magnets, and $S$ is the area of permanent magnets.
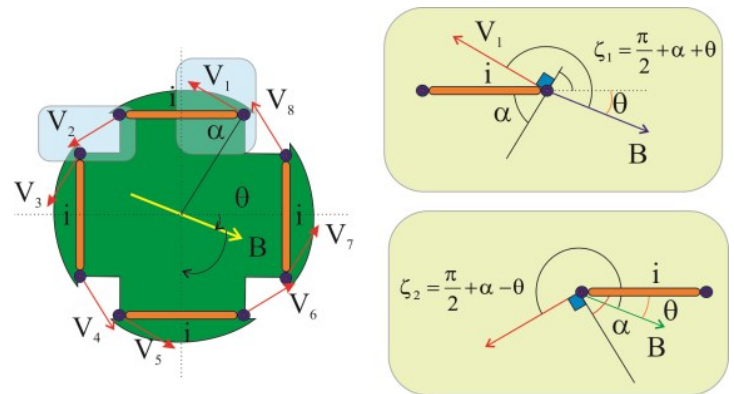

Fig. 3. The structure of a quadratic rotor at the parallel connection and the orientation of the magnetic flux vectors along with the definition of the angles $\xi_{1}, \xi_{2}$.

The electromagnetic moments in the other windings are determined in a similar way. Therefore

$$
\begin{gathered}
M_{2}=n S B i \cos \left(\theta+\frac{\pi}{2}\right)=-n S B i \sin \theta \\
M_{3}=n S B i \cos \theta \\
M_{4}=-n S B i \sin \theta
\end{gathered}
$$

Hence, the rotational electromagnetic torque of a synchronous machine with a four pole rotor is described by the equation

$$
\begin{aligned}
M_{e m}=M_{1}+M_{2} & +M_{3}+M_{4} \\
& =2 n S B i(\cos \theta-\sin \theta) \\
& =2 \sqrt{2} n S B i_{3} \sin \left(\theta+\frac{\pi}{2}\right)
\end{aligned}
$$

In the case of a parallel connection of the resistive elements, the torque of the synchronous motor is defined as

$$
M_{e m}=n S B\left[\cos \theta\left(i_{1}+i_{3}\right)-\sin \theta\left(i_{2}+i_{4}\right)\right]
$$

where $i_{1}, i_{2}, i_{3}, i_{4}$ are the currents flowing through the coils. Other sizes occurring in the equation have the same meaning as in earlier mathematical expressions.

Further mathematical considerations assume that all four coils have the same inductance. In this situation, the equation describing the dynamic phenomena occurring in the synchronous motor will take the form

$$
J \frac{d^{2} \theta}{d t^{2}}=M_{e m}-M_{1}
$$

where $\theta$ corresponds to the mechanical rotation angle of the rotor; $M_{e m}$ is the total electromagnetic torque with respect to systems that perform engine control functions. The next step is to determine the voltage equations for the substitute serial circuit defining a four-pole synchronous motor. Fig. 3 shows the replacement circuit diagram of the electrical rotor of the synchronous machine PMSM. Turning to the next stage of mathematical analysis, it is important to consider the system shown in Figure 2.

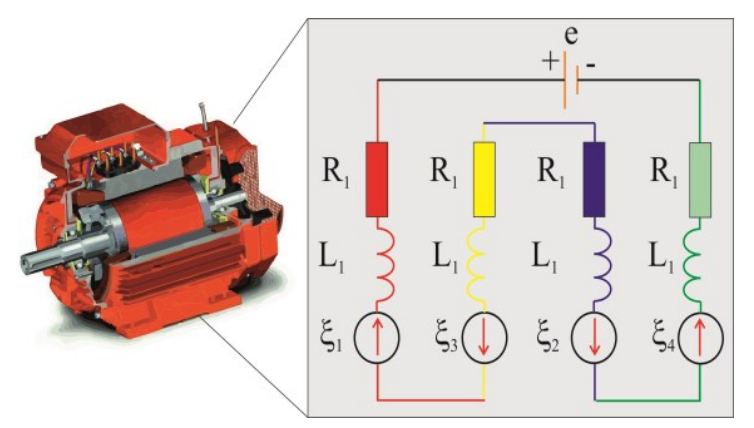

Fig. 4. Circuit diagram of a four-pole rotor circuit in serial connection

Thus, for each coil alternating current is defined in the same manner as in the previous considerations and taking into account Kirchhoff's second law to the closed circuit and taking the positive direction of the eyelet perimeter in layout of the analyzed substitute circuit arrangement according clockwise, the differential equation was defined [11], [12]

$$
L \frac{d i}{d t}+R i=F_{1}-F_{2}+F_{3}-F_{4}+e
$$

where $R, L$ denote the resistance and inductance respectively in each coil; $F_{k}$ determines the value of the electromotive force present in the k-coil as a result of the rotation of the rotor, and $e$ is a voltage source. The directions of electromotive force are illustrated in Fig. 3. Thus, according to the law of electromagnetic induction, the electromotive force generated in the coil as a result of electromagnetic field radiation and rotor rotation is defined by the formula

$$
F_{1}=l_{0} B v_{1} \sin \varphi_{1}+l_{0} B v_{2} \sin \varphi_{2}
$$

where $v_{1}, v_{2}$ represent respectively the velocity of change of the electromagnetic field relative to the coils, as illustrated in Fig. 4, and $\varphi_{1}, \varphi_{2}$ represent the angles between the velocity vector and the electromagnetic field vector. Such a solution is depicted in Fig. 5. In view of the above, the following was obtained

$$
\begin{aligned}
F_{1}=-n l_{0} B l \omega[ & \sin \left(\frac{\pi}{2}+\alpha+\theta\right) \\
& \left.+\sin \left(\frac{\pi}{2}+\alpha-\theta\right)\right] \\
& =-n\left(2 l_{0} l \cos \alpha\right) B \omega \cos \theta \\
& =-n S B \omega \cos \theta
\end{aligned}
$$

where $\omega=\frac{d \theta}{d t}$. The electromotive forces on the remaining coils, as described by the following equations, were determined in the same way

$$
\begin{aligned}
& F_{2}=-n S B \omega \sin \theta \\
& F_{3}=-n S B \omega \cos \theta \\
& F_{4}=-n S B \omega \sin \theta
\end{aligned}
$$


In contrast to a serial electrical circuit of the rotor, an equivalent circuit of parallel connection illustrated in Fig. 5, operates in closed feedback loop. Thus, by using the second Kirchhoff's law for each eyelet separately, choosing the positive direction of the eyelet circuit analyzed in a substitute circuit arrangement clockwise, as in the previous mathematical analysis.

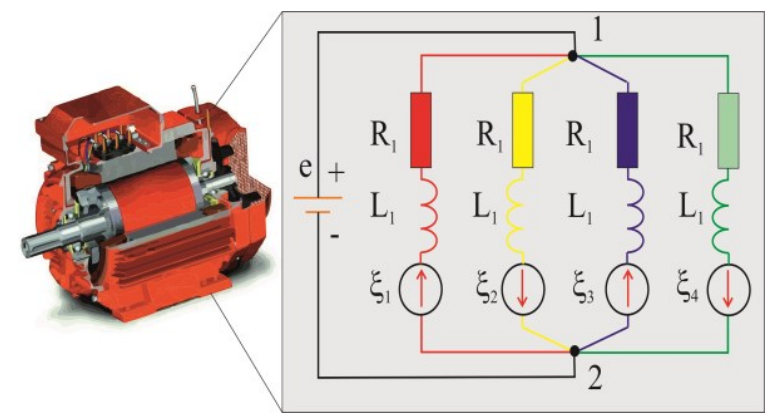

Fig. 5. Equivalent circuit diagram of a four pole rotor circuit connected in parallel

On this basis, the following differential equations were found to determine the currents in the circuit

$$
\begin{aligned}
& L \frac{d i_{1}}{d t}+R i_{1}=F_{1}+e=-n S B \omega \cos \theta+e \\
& L \frac{d i_{2}}{d t}+R i_{2}=-F_{2}+e=n S B \omega \sin \theta+e \\
& L \frac{d i_{3}}{d t}+R i_{3}=F_{3}+e=-n S B \omega \cos \theta+e \\
& L \frac{d i_{4}}{d t}+R i_{4}=-F_{4}+e=n S B \omega \sin \theta+e
\end{aligned}
$$

The values of the electromotive forces in the parallel circuit are determined identically as they have been before in equations (10) and (11). Thus, the dynamics of operation (action) of a 4-pole synchronous motor in the case of a serial connection can be described by the following differential equations

$$
\begin{gathered}
\frac{d \theta}{d t}=\omega \\
J \frac{d \omega}{d t}=2 \sqrt{2} S B i \sin \left(\frac{\pi}{4}-\theta\right)-M_{J} \\
L \frac{d^{2} i}{d t^{2}}+R i=2 \sqrt{2} S B i \sin \left(\frac{\pi}{4}-\theta\right)+e
\end{gathered}
$$

Accordingly, for parallel connection were obtained

$$
\begin{gathered}
\frac{d \theta}{d t}=\omega \\
J \frac{d \omega}{d t}=n S B\left[\cos \theta\left(i_{1}+i_{3}\right)-\sin \theta\left(i_{2}+i_{4}\right)\right] \\
L \frac{d i_{1}}{d t}+R i_{1}=-n S B \omega \cos \theta+e \\
L \frac{d i_{2}}{d t}+R i_{2}=n S B \omega \sin \theta+e \\
L \frac{d i_{3}}{d t}+R i_{3}=-n S B \omega \cos \theta+e \\
L \frac{d i_{4}}{d t}+R i_{4}=n S B \omega \sin \theta+e
\end{gathered}
$$

As mentioned earlier, most modern synchronous motors are used in advanced electric aircrafts systems (Airbus,
Boeing, Lockheed Martin), they incorporate additional damping windings to reduce power losses in the initial phase of synchronous machine start-up. Damping windings in synchronous motors are mounted in the form of cages. Considering in the mathematical analysis of damping windings, the current equation assumes the following form

$$
\begin{gathered}
L_{1} \frac{d j_{k}}{d t}+R_{1} j_{k}=-r_{0} l_{1} B \cos \left(\theta+\frac{2 k \pi}{n_{1}}\right) \frac{d \theta}{d t}, \\
k=1, \ldots, n_{1}
\end{gathered}
$$

In turn, the electromagnetic torque of the damping winding is described by the equation

$$
M_{\text {emuł }}=r_{0} l_{1} B \sum_{k=1}^{n_{1}} \cos \left(\theta+\frac{2 k \pi}{n_{1}}\right)
$$

where $n_{1}$ is the number of poles; $j_{k}$ current in the $\mathrm{k}-$ th damping winding; $L_{1}$ inductance of damping winding; $\mathrm{R}$ resistance of damping winding; $r_{0}$ and $l_{1}$ denote the radius and length of the single cage as part of the damping winding, respectively.

In practical applications, the electromagnetic fields of the damping winding and the rotor are presented as two independent, so in the case of a serial connection of the substitute circuit of a four pole synchronous motor, the mathematical model is as follows [13]

$$
\begin{gathered}
\frac{d \theta}{d t}=\omega \\
J \frac{d \omega}{d t}=2 \sqrt{2} S B i \sin \left(\frac{\pi}{4}-\theta\right) \\
+r_{0} l_{1} B \sum_{k=1}^{n_{1}} \cos \left(\theta+\frac{2 k \pi}{n_{1}}\right) j_{k} \\
-M_{J} \\
L \frac{d i}{d t}+R i=-2 \sqrt{2} S B i \sin \left(\frac{\pi}{4}-\theta\right)+e \\
L \frac{d j_{k}}{d t}+R j_{k}=-r_{0} l_{1} B \cos \left(\theta+\frac{2 k \pi}{n_{1}}\right) \frac{d \theta}{d t}, \\
k=1, \ldots, n_{1}
\end{gathered}
$$

And for parallel connection obtained

$$
\begin{gathered}
\frac{d \theta}{d t}=\omega \\
J \frac{d \omega}{d t}=n S B\left[\cos \theta\left(i_{1}+i_{3}\right)-\sin \theta\left(i_{2}+i_{4}\right)\right] \\
+r_{0} l_{1} B \sum_{k=1}^{n_{1}} \cos \left(\theta+\frac{2 k \pi}{n_{1}}\right) j_{k} \\
-M_{J} \\
L \frac{d i_{1}}{d t}+R i_{1}=-n S B \omega \cos \theta+e \\
L \frac{d i_{2}}{d t}+R i_{2}=n S B \omega \sin \theta+e \\
L \frac{d i_{3}}{d t}+R i_{3}=-n S B \omega \cos \theta+e \\
L \frac{d i_{4}}{d t}+R i_{4}=n S B \omega \sin \theta+e
\end{gathered}
$$




$$
\begin{gathered}
L_{1} \frac{d j_{k}}{d t}+R_{1} j_{k}=-r_{0} l_{1} B \cos \left(\theta+\frac{2 k \pi}{n_{1}}\right) \frac{d \theta}{d t}, \\
k=1, \ldots, n_{1}
\end{gathered}
$$

After making proper transformations, among others, by properly rearranging the size and adding additional parameters, obtained

$$
\begin{gathered}
\vartheta=-\theta-\frac{3 \pi}{4} \\
s=-\omega \\
x=i+\frac{e}{R} \\
\mu=-\frac{2 L_{1}}{n_{1} r_{0} l_{1} B} \sum_{k=1}^{n_{1}} i_{k} \sin \left(\theta+\frac{2 k \pi}{n_{1}}\right) \\
v=-\frac{2 L_{1}}{n_{1} r_{0} l_{1} B} \sum_{k=1}^{n_{0}} i_{k} \sin \left(\theta+\frac{2 k \pi}{n_{1}}\right) \\
z_{k}=\sum_{k=-\frac{n_{1}}{4}}^{\frac{n_{1}}{4}} i_{(k+j)}+i_{k} \operatorname{ctg} \frac{\pi}{n_{1}}, \quad k=3, \ldots, n_{1}
\end{gathered}
$$

As a result obtained

$$
\begin{gathered}
\frac{d \vartheta}{d t}=s \\
\frac{d s}{d t}=a x \sin \vartheta+b v-\delta_{1}(\vartheta) \\
\frac{d \mu}{d t}=-c_{1} \mu+v s \sin \vartheta \\
\frac{d x}{d t}=-c_{1} x+d s \\
\frac{d v}{d t}=-c_{1} v-s \mu-s \\
\frac{d z_{k}}{d t}=-c_{1} z_{k}, \quad k=3, \ldots, n_{1}
\end{gathered}
$$

where

$$
\begin{gathered}
a=2 \sqrt{2} \frac{n B S}{J} ; \quad b=\frac{n_{0}\left(S_{0} B\right)^{2}}{J} ; \quad c=\frac{R}{L} ; \quad c_{1} \\
=\frac{R_{1}}{L_{1}} ; \quad d=2 \sqrt{2} \frac{n B S}{L} \\
\gamma_{\max }=2 \sqrt{2} \frac{n B S e}{J R} ; \quad \gamma_{1}=\frac{M_{1}}{J} \\
\delta_{1}(\vartheta)=\gamma_{\max } \sin \vartheta-\gamma_{1}
\end{gathered}
$$

In addition, it should be noted that in the equations specified by the number (20) in its last expression the magnitude does not affect the other differential equations and the stability of the induction motor. Therefore, the following considerations only consider the following mathematical relations

$$
\begin{gathered}
\frac{d \vartheta}{d t}=s \\
\frac{d s}{d t}=a x \sin \vartheta+b v-\delta_{1}(\vartheta) \\
\frac{d \mu}{d t}=-c_{1} \mu+v s \sin \vartheta
\end{gathered}
$$

$$
\begin{gathered}
\frac{d x}{d t}=-c_{1} x+d s \\
\frac{d v}{d t}=-c_{1} v-s \mu-s
\end{gathered}
$$

Subsequently, considering the change of permanent magnet coordinates, the following were obtained

$$
\begin{gathered}
\vartheta=\frac{\pi}{4}-\theta \\
s=-\omega \\
x=-\frac{2 L}{n S B}\left[-\left(i_{1}+i_{3}+\frac{2 e}{L}\right) \sin \theta\right. \\
\left.-\left(i_{2}+i_{4}+\frac{2 e}{L}\right) \cos \theta\right] \\
y=-\frac{2 L}{n S B}\left[-\left(i_{1}+i_{3}+\frac{2 e}{L}\right) \cos \theta\right. \\
\left.-\left(i_{2}+i_{4}+\frac{2 e}{L}\right) \sin \theta\right] \\
\mu=-\frac{2 L_{1}}{n_{1} r_{0} l_{1} B} \sum_{k=1}^{n_{0}} i_{k} \sin \left(\theta+\frac{2 k \pi}{n_{1}}\right) \\
v=-\frac{2 L_{1}}{n_{1} r_{0} l_{1} B} \sum_{k=1}^{n_{0}} i_{k} \cos \left(\theta+\frac{2 k \pi}{n_{1}}\right) \\
z_{1}=i_{1}-i_{3} \\
z_{2}=i_{2}-i_{4} \\
z_{k}=\sum_{k=-\frac{n_{1}}{4}}^{\frac{n_{1}}{4}} i_{(k+j)}+i_{k} \operatorname{ctg} \frac{\pi}{n_{1}}, \quad k=3, \ldots, n_{1}
\end{gathered}
$$

The equations presented (23), as in the previous considerations, were reduced to the following form

$$
\begin{gathered}
\frac{d \vartheta}{d t}=s \\
\frac{d s}{d t}=a y+b v-\delta_{1}(\vartheta) \\
\frac{d \mu}{d t}=-c_{1} \mu+v s \\
\frac{d x}{d t}=-c_{1} x+y s \\
\frac{d v}{d t}=-c_{1} v-s \mu-s \\
\frac{d y}{d t}=-c_{1} v-x s-s \\
\frac{d z_{k}}{d t}=-c_{1} z_{k}, \quad k=3, \ldots, n_{1} \\
\frac{d z_{1}}{d t}=-c_{1} z_{1} \\
\frac{d z_{2}}{d t}=-c_{1} z_{2}
\end{gathered}
$$

where

$$
\begin{gathered}
a=\frac{(n B S)^{2}}{J L} ; \quad b=\frac{n_{0}\left(S_{0} B\right)^{2}}{J L_{0}} ; \quad c=\frac{R}{L} ; \quad c_{1} \\
=\frac{R_{1}}{L_{1}} ; \\
\gamma_{\max }=2 \sqrt{2} \frac{n B S e}{J R} ; \quad \gamma_{1}=\frac{M_{1}}{J} \\
\delta_{1}(\vartheta)=\gamma_{\max } \sin \vartheta-\gamma_{1}
\end{gathered}
$$


In addition, it should be noted that the variable $z_{k}$ has no effect on the stability of the synchronous machine, so the differential equations describing engine operation can be written as follows

$$
\begin{gathered}
\frac{d \vartheta}{d t}=s \\
\frac{d s}{d t}=a y+b v-\delta_{1}(\vartheta) \\
\frac{d \mu}{d t}=-c_{1} \mu+v s \\
\frac{d x}{d t}=-c_{1} x+y s \\
\frac{d v}{d t}=-c_{1} v-s \mu-s \\
\frac{d y}{d t}=-c_{1} v-x s-s
\end{gathered}
$$

Thus, the mathematical equations describing the dynamics of a 4-pole motor with a damping winding at different types of connection are limited only to the mathematical relations represented by the expressions (22) and (26).

\section{Simulation of selected components of the ASE system according to the concept of MEA}

Derived mathematical relationships (model) describing the physical phenomena occurring in the PMSM synchronous electric motor (engine) were subjected to a simulation verification performed in the Matlab/ Simulink programming environment [14], [15]. In the next step, using the available mathematical functions and blocks to map the individual electronic components, a synchronous motor model was developed for the operation of the electrical network of the aircraft [16]. The basic technical parameters characterizing the synchronous electric machine PMSM in the form of an electric motor were selected according to units referenced to the three-phase permanent magnet synchronous motor rating, namely $\mathrm{R}_{\mathrm{s}}=0.2 \Omega ; \mathrm{L}_{\mathrm{d}}=\mathrm{L}_{\mathrm{q}}=$ $\mathrm{L}_{\mathrm{s}}=0.0085 \mathrm{H} ; \Psi_{\mathrm{PM}}=0.175 \mathrm{Vs} ; \mathrm{p}=4$. The magnitude of $R_{s}$ the substitute resistance of the motor circuit; and $L_{d}$, $L_{q}, L_{s}$ are the inductances of the coils contained in the motor. In turn, the parameter $\Psi_{P M}$ is responsible for the value of the electromagnetic flux, and $p$ is the number of permanent magnets. Synchronous motor block diagram designed in Matlab/Simulik is shown in Fig. 6.

\section{Permanent Magent Synchronous Motor}

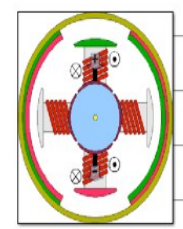

Sine Wave
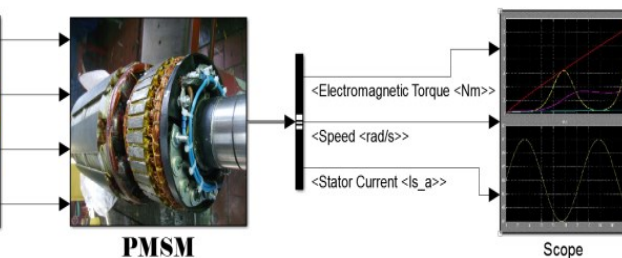

Scope
Fig. 6. Model of synchronous motor in Matlab/Simulink program
It is important to note that during the start-up of a permanent magnet-driven motor, the position of the stator field and rotor field axes is important. This can also be demonstrated by analyzing the rotational speed during start-up of the motor for the various phases of the stator start-up phase. The next figure (Fig. 7) shows the engine rotational speed charts for the extreme rotor positions relative to the initial supply voltage phase of 0 and $180^{\circ}$. The results of the simulations are shown in Figs. 7 to 9 .

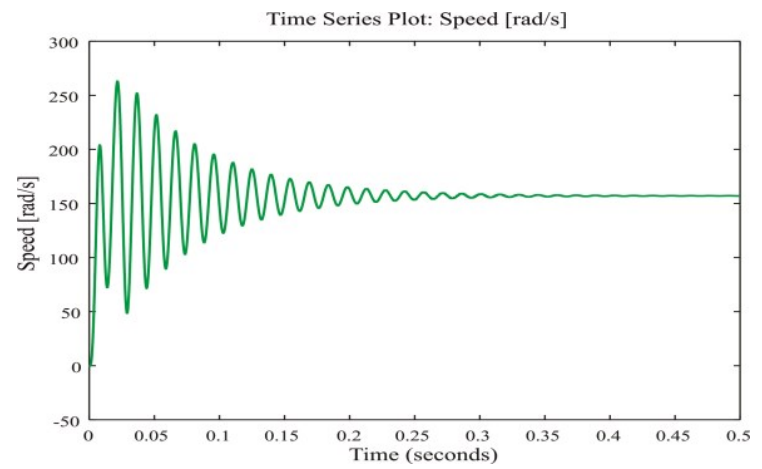

Fig. 7. Rotational speed diagram of the synchronous motor

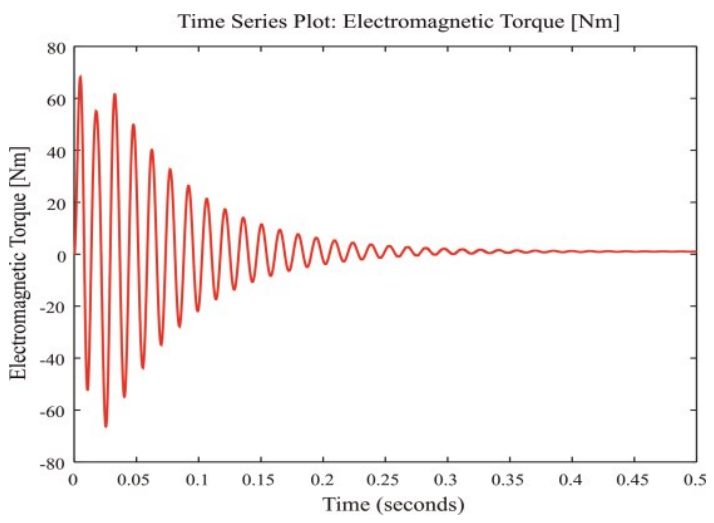

Fig. 8. Electromagnetic torque diagram of synchronous motor

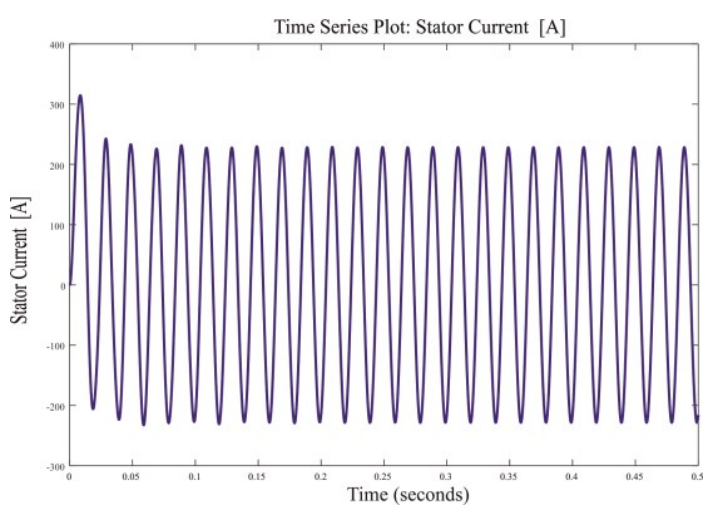

Fig. 9. Diagram of current waveform in synchronous motor

Presented waveforms representing the electromagnetic torque and rotational speed occurring during the start-up process and during further operation of the motor acquire the characteristic waveform of a sinusoidal wave with varying amplitude and duration, but with a constant frequency value. The shape of the curves in both cases resembles an oscillating signal which, after a certain time, converts into a straight line. In addition, the current 
characteristic of the synchronous motor circuit is a curve that is characterized by some fluctuations at the very start of the motor start-up, followed by a sinusoidal waveform. It should be added that the resulting initial fluctuations result from the starting of an electric motor. The start-up properties of PMSM electrical machines have a direct impact on their operation. In turn, the braking torque from permanent magnets, occurring in the lower speed range, significantly impedes the start-up process. Thanks to the measured short-circuit characteristics, the elements of the calculation model (such as face-inductance and material parameters) were significantly modified from the standpoint of start-up characteristics, followed by average torque values and static mechanical characteristics (Fig. 8).

Additionally, the graph shows that the starting torque of the motor is sufficiently large, even when the voltage is applied, including the possible voltage drop (17\%). Calculations were made assuming that the engine was loaded with electronic equipment (load compatible with the technical requirements according to the standards used in more electric aircraft) for the moment of inertia equal to 1.2 the moment of inertia of the motor rotor of the PMSM electrical machine.

\section{Conclusions}

Modern synchronous motors with permanent magnets in the electrical network of aircraft compatible with the concept of a more electric aircraft have very good regulatory characteristics and are characterized by high efficiency and high torque overload. These properties are confirmed by the diagrams shown in Figs. 7 to 9. In addition, it should be added that high torque momentum becomes a key parameter for the selection of motors in electrical drives that produce electricity.

Because of the motor nature of the high instantaneous overload, the mass and rated capacities of the motors used in electric aviation engines can be reduced to a large extent. In addition, the use in permanent magnet motors of standard spread sheets used in asynchronous motors can significantly reduce the cost of production of these motors, but they are not optimized for maximum torque. Consequently, stator and rotor plates must be designed to achieve the best operating parameters of permanent magnet motor. However, it is not feasible to design such a motor that would have all the key technical parameters at a very high level. In addition, motors for various applications will have different parameters and the designer should decide what parameters are the most important for an engine to adequately design the motor electromagnetic circuit (Figs. 7 to 9).

Current permanent magnet engine designs are strictly dedicated to a particular drive, where the most important parameter is the engine mass or power density from the unit of volume. To make full use of the power of permanent magnet motors, the motor should be powered by a dedicated power converter. Based on the obtained simulations it can be stated that by designing a synchronous motor, its properties can be independent of possible changes of the mains voltage (this includes e.g. power factor). This phenomenon plays a special role in power supply networks in aircraft in line with the trend of more electric aircraft [17]. In addition, be sure to include power supply impedance and voltage drop during design to ensure (guarantee) sure start-up and synchronization of the motor. Furthermore, since the design of such an engine, adapted to specific power and load conditions, is tailored to individual requirements, it is characterized by high energy efficiency with maximum efficiency and power factor.

\section{References}

1. Abdel-Fadil R., Eid A., Abdel-Salam M., Electrical distribution power systems of modern civil aircrafts, 2nd International Conference on Energy Systems and Technologies, Cairo, Egypt 2013.

2. Setlak L., and Kowalik R., Mathematical modeling and simulation of selected components on-board autonomous power supply system (ASE), in accordance with the concept of a more electric aircraft (MEA), 2017 18th International Scientific Conference on Electric Power Engineering (EPE) Kouty nad Desnou, Czech Republic, pp. 1-6, IEEE 2017.

3. Moir I., Seabridge A., Design and Development of Aircraft Systems, Second Edition, John Wiley \& Sons, Ltd., 2013.

4. Krause P.C., Wasynczuk O., Sudhoff S.D., Analysis of Electrical Machinery and Drive Systems, IEEE Press, John Wiley \& Sons, Inc., 2002.

5. Parker R., Horizon 2020 Industrial Technologies as an Engine of Growth, Rolls-Royce, Presentation 2012.

6. Zhao X., Guererro J.M., Wu X., Review of Aircraft Electric Power Systems and Architectures, International Energy Conference (ENERGYCON), IEEE 2014.

7. Setlak L., Overview of Aircraft Technology solutions compatible with the concept of MEA, Technical Transactions. Electrical Engineering, No. 1-E/2015, p. 67-76, Cracow University of Technology 2015.

8. Toliyat H.A., and Kliman G.B., Handbook of Electric Motors, Taylor and Francis. Electrical and computer engineering, 850, (2010).

9. Singh B., Murthy S.S, and Gupta S., Analysis and design of STATCOM-based voltage regulator for self-excited induction generators, IEEE Trans. Energy Convers., Vol. 19, No. 4, pp. 783-790, (2004).

10. Wang L., Jatskevich J., and Dommel H.W., Reexamination of synchronous machine modeling techniques for electromagnetic transient simulations. Power Systems, IEEE Transactions on 22 (3), 1221-1230, (2007).

11. Yang Z., Qu J., Ma J., and Shi X., Modeling and Simulation of Power Distribution System in More Electric Aircraft, Hindawi Publishing Corporation 
Journal of Electrical and Computer Engineering Volume, Article ID 847624, 7 pages, 2015.

12. Cheng R., Zhao W., Deng H., and Jiang X., Modeling and Optimization Control for Aircraft AC Generator Brushless Excitation System Based on Improved Adaptive PSO, The Open Automation and Control Systems Journal, Vol. 7, 21-30, (2015).

13. Tesla N., No. 382,280, Electrical Transmision of Power, 1888.

14. Vinod Vashram Vadher, Mathematical Modelling of Aircraft Electrical Power Systems, Doctoral Thesis, Loughborough University of Technology, 1981.

15. Skvarenina T.L., Pekarek S., Wasynczuk O., and Krause P.C., Simulation of a More-Electric Aircraft Power System using an automated state model approach, Proceedings of the Intersociety Energy Conversion Engineering Conference, pp. 133-136, (1996).

16. Emandi K., Ehsani M., Aircraft power systems: technology, state of the art, and future trends, Aerospace and Electronic Systems, IEEE, 2000.

17. Setlak L., Kowalik R., Comparative Analysis and Simulation of selected Components of Modern Onboard Autonomous Power Systems (ASE) of Modern Aircraft in line with the Concept of MEA/AEA, Lecture Notes in Engineering and Computer Science, Volume 1, 2016. 